\title{
Global Boreal Forest Mapping with JERS-1: North America
}

\author{
Cynthia L. WILliAMS', Kyle MCDONALD ${ }^{(2)}$ and Bruce CHAPMAN'2 \\ (1)Alaska SAR Facility and Institute of Arctic Biology, P.O. Box 757320. \\ University of Alaska Fairbanks, Fairbanks, AK 99775-7320, USA. \\ 1-907-4747058; fax: 1-907-474-6441; cwilliam @lter.uaf.edu
(2) Jet Propulsion Laboratory, California Institute of Technology, Mail Stop 300-233, 4800 Oak Grove Drive, Pasadena, CA $91109-8099$, USA; 1-818-354-3263; fax: 1-818-354-9476 kyle.mcdonald@jpl.nasa.gov bruce.chapman@jpl.nasa.gov

\section{INTRODUCTION}

A collaborative effort is underway to map boreal forests Worldwide using L-band, single polarization Synthetic Aperture Radar (SAR) imagery from the Japanese Earth Resources (JERS-1) satellite. Final products of the North American Boreal Forest Mapping Project will include two continental scale radar mosaics and supplementary multitemporal mosaics for Alaska, central Canada, and eastern Canada. For selected sites, we are also producing local scale $(100 \mathrm{~km} \times 100 \mathrm{~km})$ and regional scale maps (1000 $\mathrm{km} \times 1000 \mathrm{~km}$ ). As with the nearly completed Amazon component of the Global Rain Forest Mapping project [13], SAR imagery, radar image mosaics and SAR-derived texture image products will be available to the scientific community on the World Wide Web. Image acquisition for this project has been completed and processing and image interpretation is underway at the Alaska SAR Facility.

\section{PARTNERS}

The Global Boreal Forest Mapping (GBFM) project is a collaboration among the Earth Observation Research Center of the National Space Development Agency of Japan (EORC, NASDA), Earth Observation Center (EOC, NASDA), Japanese Ministry of International Trade and Industry (MITI), United States NASA (National Aeronautics and Space Administration, Earth Science Enterprise Office and Terrestrial Ecology Program), the Alaska SAR Facility, Jet Propulsion Laboratory, Joint Research Centre of the European Commission, Canadian Centre for Remote Sensing, German Space Agency, and the Swedish Space Corporation.

\section{RESULTS}

In this paper we present a wide variety of early results from the North American node of the GBFM. We designed the data acquisition and products to facilitate a wide variety of investigations of land cover and temporal change. The imagery provides important baseline information about distribution and extent of woodlands, position of treeline, distribution of wetlands, and extent of major rivercourses
(Figs. 1-3). Comparisons across seasons and years will provide additional baseline information about the dynamics of short-term landscape changes driven by fire, flooding, forest pathogens, and permafrost (Fig. 4).

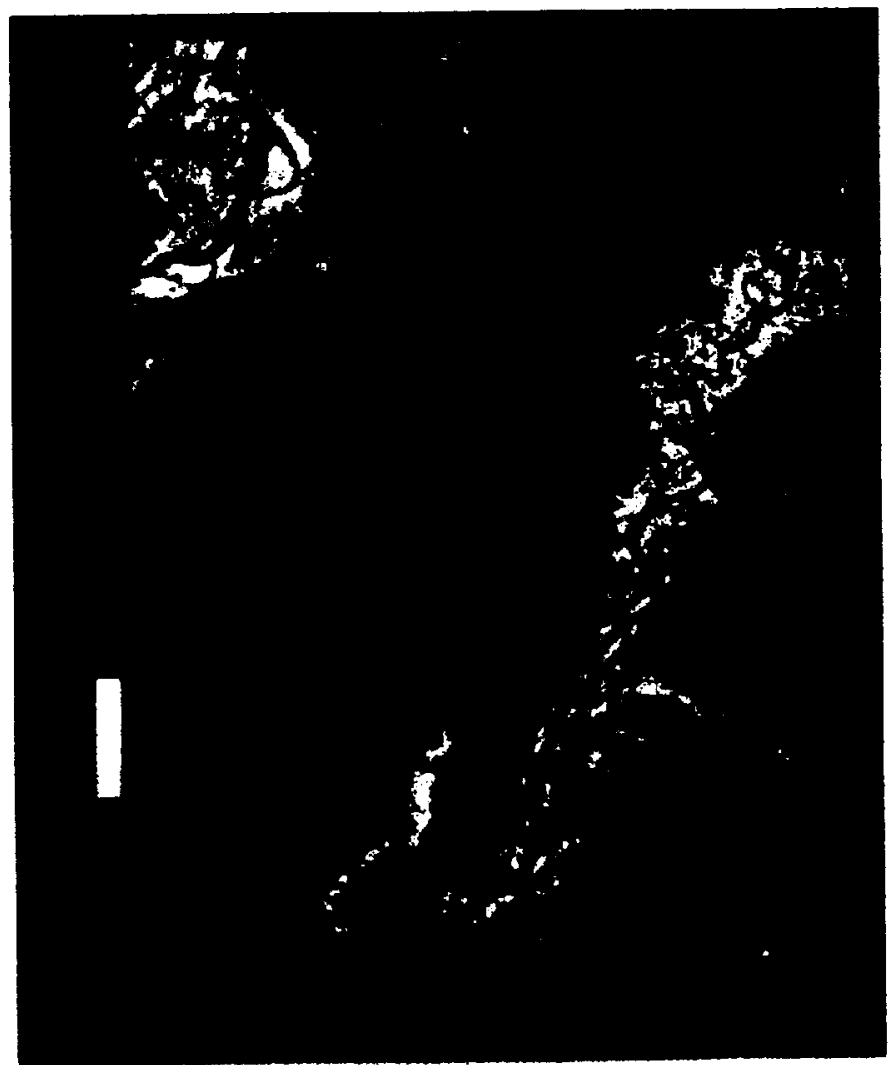

Figure 1: The Yukon (top) and Kuskokwim (bottom) rivers are separated by the wetlands of the Y-K Delta (Alaska). High biomass forests (yellow) are associated with both rivers; streams through the wetlands are bordered by lower biomass willow and alders (red). The wellands characteristically show low backsciatter (blue), with open water represented as black. In the lower right, increasing elevation inlluences drainage and vegetation, and is seen as increasing backscatter. 
Figure 2: Tanana River, Tanana Flats, Alaska, 14 April 1997. This image distinguishes the high biomass floodplain forests (red) from lower biomass black spruce forests. and wetlands (gray) in the backswamps. The Tanana Flats (bottom of the image) is a mosaic of groundwater-fed wetlands (showing inundation this time of year), open woodlands, and wooded creeks and rivers (red). Fairbanks International Airport is seen at the upper right. This section of the Tanana River floodplain and its adjacent uplands comprise the Bonanza Creek Long Term Ecological Research Site.

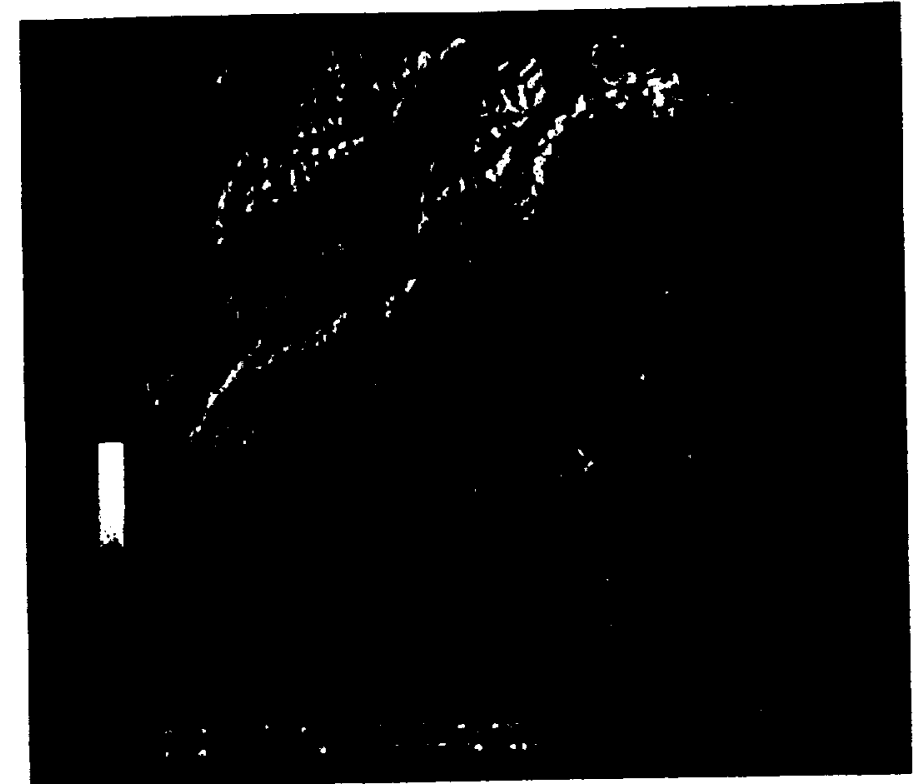

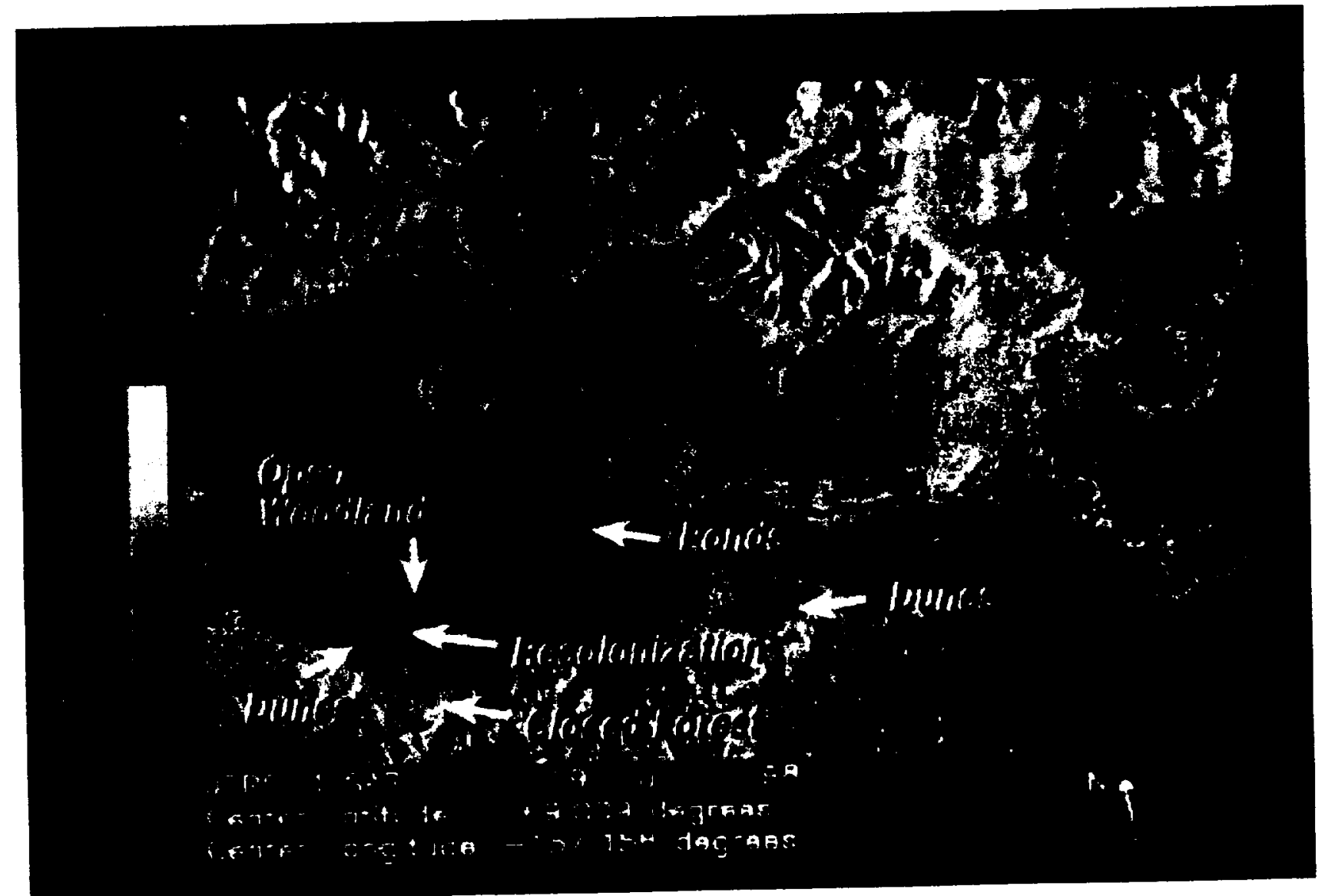

Figure 3: Kobuk River and Dunes, Alaska. 19 July, 1998. 

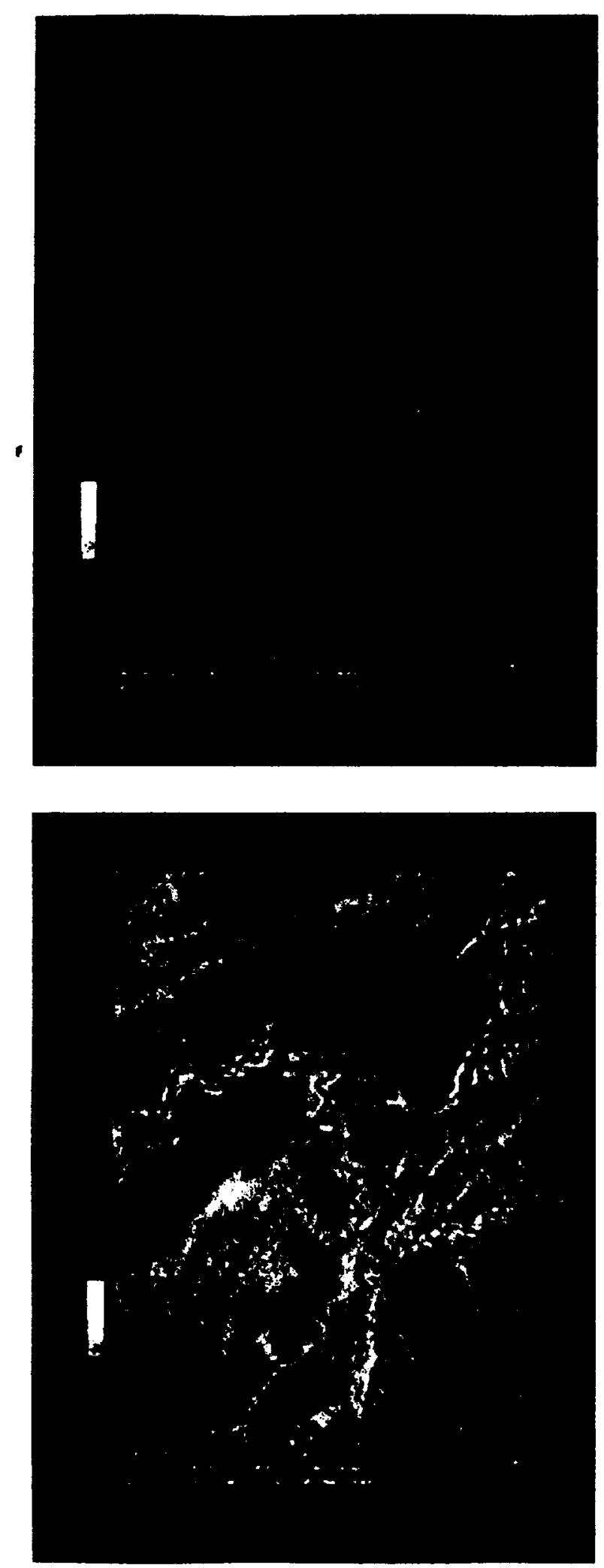

Figure 4: Tanana River, Minto Flats, Alaska. This image pair exemplifies the dramatic seasonal responses of SAR to freezing/thawing and to snow cover and wetness. Although absolute backscatter values are higher on 30 May (bottom), the relative values of many landscape components remain the same. Higher biomass floodplain forests show greater backscatter. Backscatter off wet snow cover on 16 April (top) reduces contrast among landscape components and obscures many of the Minto Lakes.

\section{DISCUSSION AND CONCLUSIONS}

SAR reliably provides the complete image coverage neoded for ecological modeling and mosaicking of large areas. This mapping project will have immediate applications for ecological modeling at regional to global scales. The extent and distribution of boreal forests worldwide are changing with growing exploitation for wood production, with changing frequency and severity of natural fires, with continuing postglacial forest expansion, and with climate-induced changes in distributions of forest species. Our results demonstrate specific applicability of these data to modeling of carbon flux in boreal ecosystems through the estimation of biomass, burning, regrowth, inundation, soil exposure, and growing season length. Dramatic changes in carbon flux with changing land cover have been predicted by a variety of ecological models; the products of this mapping project can improve the accuracy and scope of such models. Additionally, our results underline the continued utility of imaging radar for global forest monitoring efforts.

\section{REFERENCES}

[1] B. Chapman, V. Taylor, and A. Rosenquist, "Rain Forest Mapping Project to Release CD-ROMs", Eos, Transactions, Vol 79, no 35, Sept 1, 1998, page 417.

[2] A. Rosenqvist, "The Global Rain Forest Mapping Project by JERS-1 SAR", Proc of XVIII ISPRS Cong., Vienna,A ustria, 1996.

[3] Chapman, B., http://southport.jpl.nasa.gov/GRFM

This work was performed at the University of Alaska Fairbanks and at the Jet Propulsion Laboratory. Califormia Institute of Technology, under contract to the National Aeronautics and Space Administration. 